\title{
Disparities in obesity among rural and urban residents in a health disparate region
}

\author{
Jennie L Hill ${ }^{* *}$, Wen You ${ }^{2}$ and Jamie M Zoellner ${ }^{1}$
}

\begin{abstract}
Background: The burden of obesity and obesity-related conditions is not borne equally and disparities in prevalence are well documented for low-income, minority and rural adults in the United States. The current literature on rural versus urban disparities is largely derived from national surveillance data which may not reflect regional nuances. There is little practical research that supports the reality of local service providers such as county health departments that may serve both urban and rural residents in a given area. Conducted through a community-academic partnership, the primary aim of this study is to quantify the current levels of obesity (BMI), fruit and vegetable (FV) intake and physical activity (PA) in a predominately rural health disparate region. Secondary aims are to determine if a gradient exists within the region in which rural residents have poorer outcomes on these indicators compared to urban residents.
\end{abstract}

Methods: Conducted as part of a larger ongoing community-based participatory research (CBPR) initiative, data were gathered through a random digit dial telephone survey using previously validated measures $(n=784)$. Linear, logistic and quantile regression models are used to determine if residency (i.e. rural, urban) predicts outcomes of FV intake, $\mathrm{PA}$ and BMI.

Results: The majority (72\%) of respondents were overweight (BMI $\left.=29 \pm 6 \mathrm{~kg} / \mathrm{m}^{2}\right)$, with $29 \%$ being obese. Only $9 \%$ of residents met recommendations for FV intake and 38\% met recommendations for PA. Statistically significant gradients between urban and rural and race exist at the upper end of the BMI distribution. In other words, the severity of obesity is worse among black compared to white and for urban residents compared to rural residents.

Conclusions: These results will be used by the community-academic partnership to guide the development of culturally relevant and sustainable interventions to increase PA, increase FV intake and reduce obesity within this health disparate region. In particular, local stakeholders may wish to address disparities in BMI by allocating resources to the vulnerable groups identified.

Keywords: Community-based participatory research, Physical activity, Fruit and vegetable intake, Health disparities

\section{Background}

Prevalence of obesity among adults is epidemic in the United States [1-3]. The burden of obesity and obesityrelated conditions is not borne equally as low-income and minority populations suffer higher prevalence of obesity and increased co-morbid conditions [4-9]. Additionally, disparities in obesity and obesity-related conditions are evident by geographic location. Notably, the southern states in the U.S. have higher burdens of obesity than northern states. Nation-wide, rural populations exhibit higher prevalence of obesity and obesity-related outcomes

\footnotetext{
* Correspondence: hillj@@t.edu

'Department of Human Nutrition, Foods and Exercise, Virginia Tech, Blacksburg, Virginia, USA

Full list of author information is available at the end of the article
}

such as type 2 diabetes [10-12]. Rates of mortality and morbidity from chronic health conditions are higher among rural populations when compared to their urban or suburban counterparts $[10,11,13]$.

From social determinants of health framework, increased prevalence of obesity in rural populations stems in part, from 'downstream' behavioral factors such as physical inactivity and poor diet among rural populations [11,12,14]. However, these behavioral patterns are influenced by 'upstream' determinants such as lower educational attainment and lower SES also characterizing many rural areas [15]. Additional structural constraints in rural regions including lack of medical providers and increased distances to obtain medical care act to perpetuate disparities in health 
outcomes $[9,16]$. Additionally, rural residents may lack access to primary prevention efforts and reduced access to the facilities or amenities that foster healthy behaviors (i.e. recreations centers, grocery stores) [17-19]. Understanding the causes of these disparities is essential to the development and implementation of effective interventions to address obesity and its related conditions in rural regions [5].

The delivery of prevention services in rural areas is further hindered by the logistics of serving hard-to-reach populations dispersed over large geographic areas $[17,19]$. The current literature exploring disparities by rural or urban residency is typically based on national or state level surveillance data. While these data provide important information to understand disparities, they do not necessarily reflect the reality of service providers such as county health departments or private healthcare systems that may serve both urban and rural residents in a given region. Further, small- to mid-sized cities are certainly 'urban' compared to rural areas, but they may not have the same population density or access to resources that is typical of urban or suburban population centers. There is little practical research that considers these types of regions. Yet there is a need to develop health promotion strategies that address the resources and delivery systems in these regions to maximize sustainability of programs.

Community-based participatory research (CBPR) is one method by which researchers can reach vulnerable populations and leverage local expertise to aid in the identification of the problem and solutions [20-22]. The Dan River Partnership for a Healthy Community (DRPHC) is a community-academic partnership operating under CBPR principles in the health disparate Dan River Region (DRR) [23,24]. To support community-created causal models for obesity [23] and initiatives by the DRPHC, the need for locally generated surveillance data on health outcomes and behavioral factors related to obesity was identified as a priority. Importantly, the overall goal was to provide baseline data for the DRPHC to evaluate the success of obesity-related initiatives and to effectively identify target populations for programming aimed at reducing obesity in the region. Therefore, the primary aim of the current study is to quantify the current levels of obesity and the related behavioral determinants of fruit and vegetable intake (FV) and physical activity (PA) in the region. Secondary aims are to determine if differences in these health behaviors and outcomes exist based on socio-demographic characteristics and to determine if a gradient exists within the region in which rural residents have poorer health outcomes compared to those who live in town. As compared to urban residents, we hypothesized those residing in the outlying rural counties as well as those with lower educational attainment and minority groups would demonstrate higher BMIs, lower rates of PA and lower FV intake.

\section{Methods}

All study activities were approved by Virginia Tech IRB and survey participants provided verbal informed consent prior to completing study activities.

\section{Study area}

The DRR, an educationally and economically disadvantaged region in south central Virginia and north central North Carolina, is federally designated as a medically under-served area/population (MUA/MUP) [25-27]. Geographically the region includes 3 counties covering approximately 1,800 square miles $\left(\mathrm{mi}^{2}\right)$ with a total population across counties of 137,000 [28]. Using the USDA Rural Urban Community Area Codes (RUCAs), all census tracts in the 3 counties are classified as rural with RUCA codes $>4$ [29]. Population density in the Virginia counties is 65.5 and 141.6 persons/ $\mathrm{mi}^{2}$ and in the North Carolina county 55.8 persons $/ \mathrm{mi}^{2}$ while the state-wide population density is 202.0 and 191.1 persons $/ \mathrm{mi}^{2}$ for Virginia and North Carolina [28]. This predominately rural area is anchored by a mid-size regional city (approximately 43,000 residents) covering $44 \mathrm{mi}^{2}$ and another nearby town of approximately 10,000 residents. Resources for the region, including healthcare, retail, institutions of higher education, and large employers are located within the regional city. Thus, while the DRR is rural region, community partners largely recognize those residents living within the regional city and town have access to resources that may be dramatically different than those in the outlying county. For the purposes of this study, we define 'urban' residents as those who live within the city limits of the aforementioned city and town. Residents who live outside the city limits are classified as 'rural'. Based on those urban and rural classifications, the rural population for our study area is $70 \%$ white and $26 \%$ black with a mean household income of $\$ 46,986$ and $9 \%$ of the rural population has a 4-year college degree. While the urban population is about $49 \%$ white and $47 \%$ black; with a mean household income of $\$ 43,316$ and $11 \%$ with a 4 -year college degree [28].

\section{Data collection Sampling}

A professional survey unit was contracted to create sampling frames and conduct the telephone survey. A random proportional sampling frame was created based on the population for each of the aforementioned 3 counties and the 2 cities, including listed and unlisted land lines and cell phone numbers. Working in collaboration with community partners, the DRPHC initiated a regional media blitz approximately 2 weeks prior to the survey 
unit initiating phone calls to enhance participation in the telephone survey. Informational emails and flyers were distributed through DRPHC member list serves for printing and circulation. Additional print and audio announcements were distributed through local media including newspapers, radio shows and television programming. These announcements provided information on the DRPHC, the purpose of the telephone survey and encouraged residents to answer and complete the survey if contacted by the survey unit. The survey took approximately 25 minutes and all participants in the random and non-random sample received a \$20 gift card for completion of the telephone survey.

\section{Survey development and testing}

Modeled after the Virginia and National Behavioral Risk Factor Surveillance System (BRFSS) surveys for 2011 [30], the telephone survey was comprised of ten modules. The modules reported here include socio-demographics, physical activity, fruit and vegetable intake and BMI. The survey unit conducted a pre-test within the region $(\mathrm{n}=22)$, resulting in minor adaptions to wording and detailed instructions and clarifications for the survey unit. Results from the pilot test were not significantly different than the full sample therefore the pilot respondents are included for analyses.

\section{Outcome measures}

The valid and reliable Godin-Shephard leisure time exercise questionnaire [31] measured minutes of PA and it was scored according to published protocols. Physical activity is reported as minutes/week of physical activity and meeting recommendations is defined using the 2008 Physical Activity Guidelines for adults as $>150$ minutes of moderate-vigorous activity and 2 days strength training [32]. The valid and reliable National Cancer Institute Fruit and Vegetable screener measured FV intake [33]. This short screener asks participants to report on the frequency and portion size for nine different food items, and is appropriate for population based surveillance and telephone surveys $^{31}$. Both fruit and vegetable intake (FV) is reported as mean servings/day and meeting recommendations is defined as $>5$ cups/day. Using the established $\mathrm{kg} / \mathrm{m}^{2}$ formula, BMI was calculated from self-reported height and weight. Socio-demographic variables including age, gender, race, income, education and employment status were also collected. Categorical socio-demographics were collapsed to eliminate empty cells.

\section{Statistical analyses}

Descriptive statistics including frequencies, means, and standard deviations were computed for the covariates, independent and dependent variables using SPSS 20.0. Using Stata 12.1, linear, logistic and quantile regression models are used to determine if residency (i.e. rural, urban or housing) predicts continuous or dichotomized outcomes of FV intake, PA and BMI. To achieve unbiased and consistent residency effects, these models control for individual level covariates including gender, race, education level and employment status. Quantile regressions were used to explore the potential heterogeneous residency effects along the outcomes' distributions.

\section{Results}

Our sample consists of 784 completed surveys (77\% response rate). Characteristics of the study sample are presented in Table 1. For the total sample, the mean age was $56( \pm 15.3)$ years. Seventy-three percent of respondents

Table 1 Characteristics of study sample by rural and urban residency

\begin{tabular}{|c|c|c|c|c|}
\hline \multirow[t]{2}{*}{ Characteristic } & \multirow{2}{*}{$\begin{array}{l}\text { Total } \\
\text { sample } \\
\mathrm{N}=784\end{array}$} & \multirow{2}{*}{$\begin{array}{l}\text { Urban } \\
n=210\end{array}$} & \multirow{2}{*}{$\begin{array}{l}\text { Rural } \\
n=574\end{array}$} & \multirow[t]{2}{*}{$p$-value } \\
\hline & & & & \\
\hline Age, $M \pm S D$ & $\begin{array}{l}56.4 \\
\pm 15.3\end{array}$ & $\begin{array}{l}61.6 \\
\pm 14.7\end{array}$ & $\begin{array}{l}59.1 \pm \\
15.6\end{array}$ & 0.14 \\
\hline Gender & $\%(n)$ & $\%(n)$ & $\%(n)$ & \\
\hline Female & $73(573)$ & $74(156)$ & $73(417)$ & 0.36 \\
\hline Race & & & & $<.001$ \\
\hline White & $76(578)$ & 68(137) & $78(441)$ & \\
\hline Black & $22(167)$ & 29(59) & 19(108) & \\
\hline More than 1 race & $2(21)$ & $3(7)$ & $3(14)$ & \\
\hline Income & & & & 0.004 \\
\hline$<\$ 20,000$ & $34(221)$ & $44(75)$ & $30(146)$ & \\
\hline$\$ 20,000-\$ 50,000$ & $39(257)$ & $32(54)$ & $42(203)$ & \\
\hline$>\$ 50,000$ & $27(178)$ & $24(42)$ & $28(136)$ & \\
\hline Education & & & & 0.65 \\
\hline$<\mathrm{HS}$ & 15(119) & $14(30)$ & 16(89) & \\
\hline HS diploma/GED & $33(224)$ & $35(72)$ & $35(202)$ & \\
\hline Some college & $31(245)$ & $30(63)$ & $31(182)$ & \\
\hline College grad or higher & $21(145)$ & $21(45)$ & $18(100)$ & \\
\hline Employment & & & & 0.01 \\
\hline Employed & $36(277)$ & $34(69)$ & $36(208)$ & \\
\hline Unemployed & $8(63)$ & $6(13)$ & $9(50)$ & \\
\hline Homemaker/Student & $8(58)$ & $6(13)$ & $8(45)$ & \\
\hline Retired & 39(301) & $38(78)$ & $39(223)$ & \\
\hline Unable to work & $9(79)$ & $16(24)$ & $8(45)$ & \\
\hline Marital Status & & & & $<.001$ \\
\hline $\begin{array}{l}\text { Married/living w/ } \\
\text { partner }\end{array}$ & $57(443)$ & 48(99) & $60(344)$ & \\
\hline Divorced/separated & 18(135) & $17(35)$ & 18(100) & \\
\hline Widowed & $15(121)$ & $20(41)$ & $14(80)$ & \\
\hline Never married & $10(46)$ & $15(32)$ & $8(46)$ & \\
\hline
\end{tabular}

*ANOVA (F-test) or $\mathrm{X} 2$ tests to determine if differences exist based rural or urban residency. 
were female, $78 \%$ white, and $30 \%$ reported income of $<\$ 20,000$. There are differences in socio-demographic characteristics by rural or urban residency for race, income, marital status and employment (Table 1). Table 2 summarizes the means and standard deviations for the primary outcomes explored in this study-FV intake, PA, and BMI.

\section{FV intake}

The average FV intake was $2.8( \pm 2.5)$ cups per day, with only $9 \%$ of the sample meeting current recommendations The average cups of FV intakes and percentage of people meeting the recommendations were both low across all groups with no significant differences $(\mathrm{F}=1.87, p=0.67$; $\mathrm{F}=0.24, p=0.50)$ based on rural $(\mathrm{M}=2.9 \pm 2.8)$ and urban $(\mathrm{M}=2.8 \pm 1.9)$.

\section{PA}

The average minutes of moderate-to-vigorous physical activity (MVPA) per week was $127 \pm 182$ and there were no significant differences based on rural $(\mathrm{M}=132 \pm 183)$ or urban $(\mathrm{M}=122 \pm 182)$ classification $(\mathrm{F}=0.47, p=0.49)$. Thirty-eight percent of the total sample meets recommendations for MVPA and there were significant differences between rural and urban, with more rural residents reporting meeting recommendation for cardiovascular physical activity $\left(\chi^{2}=6.90, p=0.005\right)$. Only $11 \%$ meet the current full PA recommendations including both cardiovascular and strength training but these were not significantly different between rural and urban residents $(\mathrm{F}=2.24, p=0.33)$.

\section{BMI}

The average BMI was $29.1 \pm 5.8$ and $40 \%$ of the sample was overweight, $29 \%$ obese and 3\% morbidly obese. Examining continuous BMI, there are no significant differences between rural and urban participants $(\mathrm{F}=2.51$, $p=0.11$ ). However, for categorical indicators of BMI, a higher percent of the rural sample was overweight and a higher percent of urban residents were obese or morbidly obese $\left(\mathrm{X}^{2}=18.38, p<.001\right)$.

Prediction of health outcomes by rural or urban residency Tables 3 and 4 illustrate regression results, accounting for individual characteristics, for continuous outcome models and dichotomous outcome models, respectively. Statistically significant (at $5 \%$ level) results are discussed here.

There is no significant residency (i.e., urban) effect for FV intake or meeting FV recommendations (Tables 3 and 4). However, on average, females consume more FV than males $(p<.05)$ and those with a college education $(p<.01)$ consume more FV than those with lower education levels. This same relationship exists for models examining the probability of meeting $\mathrm{FV}$ recommendations in which females $(\mathrm{OR}=2.14, p<.05)$ and college educated $(\mathrm{OR}=1.74, p<.05)$ participants have increased odds of meeting FV recommendations (see Table 4).

Turning to PA models, while no significant differences in minutes of MVPA by residency (Table 3), urban residents are found to be less likely to meet PA recommendation (Table $4, \mathrm{OR}=0.65, p<.05$ ) compared to their rural counterparts. An inverse relationship between gender and $\mathrm{PA}$ is shown, where on average females report fewer minutes of MVPA than males (Table 3) and the odds of

Table 2 Description including means, standard deviations and percent meeting recommendations for primary outcomes of fruit and vegetable (FV) intake, physical activity (PA) and BMI by residency

\begin{tabular}{|c|c|c|c|c|}
\hline Outcome & $\begin{array}{l}\text { Total sample } \\
(\mathrm{N}=784)\end{array}$ & $\begin{array}{l}\text { Urban } \\
(n=210)\end{array}$ & $\begin{array}{l}\text { Rural } \\
(n=574)\end{array}$ & $p$-value* \\
\hline FV intake, $M \pm S D$ cups/day & $2.8 \pm 2.5$ & $2.8 \pm 1.9$ & $2.9 \pm 2.8$ & 0.19 \\
\hline FV, \% meeting recommendations & 9 & 9 & 9 & 0.50 \\
\hline PA, Minutes of moderate-vigorous activity/week & $127 \pm 182$ & $122 \pm 182$ & $132 \pm 183$ & 0.49 \\
\hline PA, Minutes of strength training/week & $25 \pm 205$ & $18 \pm 77$ & $31 \pm 256$ & 0.65 \\
\hline PA, \% meeting recommendations ${ }^{a}$ & 38 & 31 & 41 & 0.005 \\
\hline PA, \% meeting recommendations ${ }^{b}$ & 11 & 9 & 12 & 0.33 \\
\hline $\mathrm{BMI}\left(\mathrm{kg} / \mathrm{m}^{2}\right), \mathrm{M} \pm \mathrm{SD}$ & $29.1 \pm 5.8$ & $29.0 \pm 6.8$ & $28.3 \pm 5.3$ & 0.11 \\
\hline \multicolumn{5}{|l|}{ BMI, categorical \%(n) ${ }^{+}$} \\
\hline Normal Weight (18.05-24.9) & $29(223)$ & $32(66)$ & $28(155)$ & \multirow[t]{4}{*}{$<0.001$} \\
\hline Overweight (25.0-29.9) & $35(265)$ & $24(48)$ & $39(217)$ & \\
\hline Obese (30-39.9) & $31(231)$ & $37(74)$ & $29(157)$ & \\
\hline Morbidly Obese (>40) & $5(33)$ & $7(14)$ & $4(19)$ & \\
\hline
\end{tabular}

${ }^{*} p$-value for either ANOVA (F-test) or $x^{2}$ tests to determine if differences exist based on urban or rural residency.

PA meeting recommendations ${ }^{\mathrm{a}}=>150$ minutes of moderate to vigorous activity.

PA meeting recommendations $s^{\mathrm{b}}=>150$ minutes of moderate to vigorous activity plus 2 days of strength training activities.

${ }^{+} \mathrm{N}=752, \mathrm{n}=202$ urban; $\mathrm{n}=550$ rural. Differential responses due to missing data for BMI. 
Table 3 Linear regression model to test effects of residency on $\mathrm{FV}$ intake, physical activity and weight status when controlling for covariates

\begin{tabular}{llll}
\hline Covariates & FV, Cups/day & PA, Min. of MVPA & $\mathbf{B M I}, \mathbf{~ k g} / \mathbf{m}^{2}$ \\
& $\boldsymbol{\beta}$ & $\boldsymbol{\beta}$ & $\boldsymbol{\beta}$ \\
\hline Urban & -0.10 & -4.53 & 0.55 \\
Female & $0.54^{* *}$ & $-51.09^{* *}$ & -0.56 \\
White & -0.08 & 22.00 & $-2.60^{* * *}$ \\
College & $0.54^{* *}$ & 21.19 & -0.51 \\
Employed & -0.00 & $48.99^{* *}$ & 0.33 \\
\hline
\end{tabular}

${ }^{*} \mathrm{p}<.05 ;{ }^{* *} \mathrm{p}<.01 ;{ }^{* * *} \mathrm{p}<.001$.

meeting PA recommendation for males are 2.7 times more than the odds for females $(p<.01$; Table 4$)$. Employed participants engage in more PA minutes per week than those who are unemployed $(p<.01$; Table 3$)$. Employed participants $(\mathrm{OR}=1.6, p<.001)$ and those with college degrees $(\mathrm{OR}=1.35, p<.01)$ are more likely to meet recommendations for PA than unemployed or high school-educated counterparts (Table 4).

We did not find a statistically significant relationship between residency and BMI, nor on gender, education status or employment status. However, on average, the white subgroup exhibits lower BMI levels compared to black (Table 3). When we consider BMI as a dichotomous outcome, combining overweight and obese to compare to normal weight, the race difference pattern is the same. For example, being white is protective against obesity, with $52-55 \%$ reduced odds of being overweight or obese for white residents compared to black residents (Table 4; $\mathrm{OR}=.45, p<.05$ and $\mathrm{OR}=.48, p<.01$ ). Further we tested the models stratified by race to explore differences between rural and urban residency and the dependent variables. There was not a significant effect for white/rural or white/urban on FV intake or BMI. However, for physical activity, urban whites were less likely $(\mathrm{OR}=.607, p<.05)$ to meet PA recommendations compared to rural whites. The models for black/rural and black/urban were not significant for any of the reported outcomes.
We further examine potential heterogeneous effects of demographics and residency along the BMI continuous outcome distribution. We conducted quantile regressions to determine if residency gradients exist along certain segments of the BMI distributions that may differ from the residency average effects on BMI (Figure 1). Results show that positive and statistically significant gradients between urban and rural exist among the higher end of the BMI distribution (i.e., 80th percentile or higher). In other words, among those experiencing obesity, urban residents are even heavier than their rural counterparts (Figure 1). This shows that the severity of obesity is worse for those living in town limits compared to those living in rural area in this region. Another point worth noting is that there is a similar gradient based on race. Representation of white residents is higher at the lower ends of the BMI distribution, and there is a dramatic widening for blacks at the upper end of the BMI distribution. In other words, for those with obesity, the severity of obesity is worse among black compared to white (Figure 1).

\section{Discussion}

These surveillance data provide a critical lens for identifying subgroups within the DRR that may benefit from programming targeting improvements in weight, FV, and PA outcomes. Additionally, comparing our findings to national and state level data helps the DRPHC to identify regional benchmarks and intervention targets.

In general, we demonstrate that the residents in the region fare worse on BMI compared to statewide estimates. The prevalence of obesity $(\mathrm{BMI}>30)$ at $36 \%$ is higher than statewide and national estimates of $29 \%$ and $28 \%$ respectively. Within our sample, the obesity prevalence among the urban population is $44 \%$ compared to $33 \%$ among the rural population [30].

Further, our results identify a disparity in BMI outcomes for those who are black and distinctions between urban and rural residents. Controlling for other covariates, blacks living in the region have higher BMIs than whites. The racial disparity is consistent with several other studies that

Table 4 Odds of residents meeting recommendations for FV intake, PA and weight status when controlling for covariates

\begin{tabular}{llll}
\hline & FV, Meeting recommendations ${ }^{\mathbf{a}}$ & PA, Meeting recommendations $\mathbf{b}^{\mathbf{b}}$ & BMI, overweight/obese $^{\mathbf{c}}$ \\
\hline Covariates & $\mathrm{OR}(95 \% \mathrm{Cl})$ & $\mathrm{OR}(95 \% \mathrm{Cl})$ & $\mathrm{OR}(95 \% \mathrm{Cl})$ \\
$\quad$ Urban & $0.91(0.52,1.60)$ & $0.65(0.46,0.93)^{*}$ & $0.78(0.54,1.12)$ \\
Female & $2.25(1.16,4.34)^{*}$ & $0.63(0.45,0.88)^{* *}$ & $0.74(0.51,1.08)$ \\
White & $0.85(0.49,1.48)$ & $1.19(0.83,1.71)$ & $0.48(0.31,0.72)^{* *}$ \\
College degree & $1.93(1.15,3.23)^{* *}$ & $1.46(1.07,1.98)^{*}$ & $0.74(0.79,1.58)$ \\
Employed & $0.85(0.50,1.43)$ & $1.76(1.29,2.41)^{* * *}$ & $1.12(0.79,1.58)$ \\
\hline
\end{tabular}

${ }^{*} \mathrm{p}<.05 ;{ }^{* *} \mathrm{p}<.01 ;{ }^{* * *} \mathrm{p}<.001$.

${ }^{\mathrm{a} F V}$ Meeting Recommendations $=>5$ cups of FV/day.

${ }^{b}$ PA meeting recommendations $=>150$ minutes of mod-vig activity plus 2 days of strength training activities.

${ }^{\mathrm{C}} \mathrm{BMI}$ is dichotomized to overweight/obese compared to normal weight. 

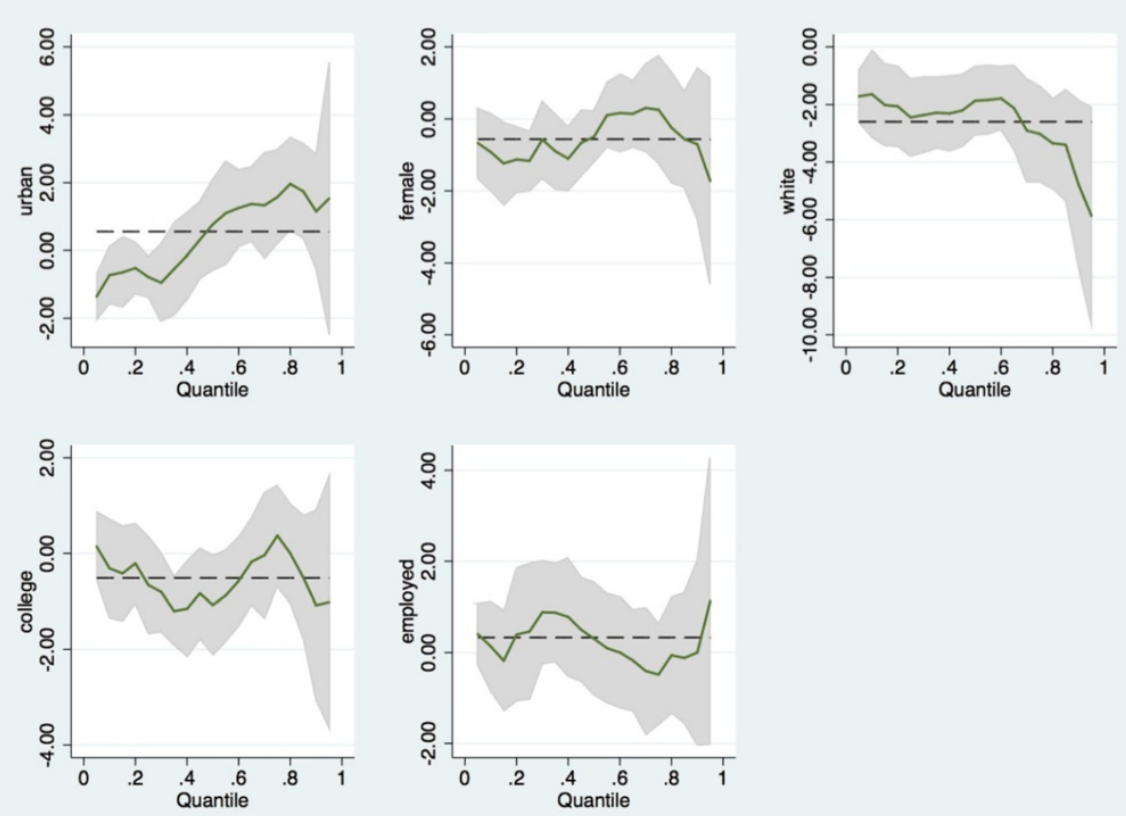

Figure 1 Quantile regression models demonstrating effects of residency and demographic factors along the BMI distribution. Note: The dependent variable is continuous BMI. The vertical axis shows the associated covariates while the horizontal axis shows the continuous BMI quantiles. The dashed lines denote the OLS regression coefficients estimates for the covariate shown in each panel; the solid lines denote the quantile regression coefficient estimates; the shaded areas are the $95 \%$ confidence intervals for the quantile estimates. Take the first panel for example: the dashed line shows the OLS estimates of the BMI differences between urban and rural (it shows that on average urban population is relatively heavier than rural but it is not statistically significant); the solid lines shows the quantile regression estimates of the BMI differences between urban and rural across the distribution of the BMI (it shows that the only statistically significant urban/rural gradient exists among those who had relatively smaller BMI).

show blacks and racial minorities have higher BMIs $[3,4,7]$. At the highest end of our BMI distribution, the gap between black and white residents widens demonstrating that more blacks are represented at the upper end. However, contradicting other national studies we find that rural residents have lower BMIs than urban counterparts, while controlling for sociodemographic factors $[10,12,14]$. Many of the studies examining rural and urban differences in health outcomes use national surveillance data such as NHANES [10,14]. It may be that those findings are not applicable to the DRR or when considering a more nuanced designation for rurality such as the USDA RUCA codes. Given the high prevalence of obesity throughout the region compared to state and national averages a comprehensive approach including treatment and primary prevention will be necessary to reduce prevalence.

Important to addressing obesity is the promotion of healthful behaviors such as increased FV and PA. Regionally, intake of FV is very low. Only 9\% of the population reported meeting recommendations compared to $27 \%$ of Virginians and $23 \%$ of Americans [30]. Our findings also indicate that participation in PA is low in the region with only $11 \%$ of the population meeting current recommendations that include cardiovascular and strength training compared to the $23 \%$ of Virginians and $29 \%$ in U.S. [34]. Due to differences in methodology and survey instruments, a precise comparison with state-level BRFSS PA is difficult. Nonetheless is it clear that few residents in this region met PA recommendation and that increasing participation in PA could help address obesity in the region.

Congruent with our hypothesis and other studies, we found that those with higher education are consuming more FV and more likely to be engaging in PA [12,34-37]. We did not find these differences to be consistent by race. Although not an a-priori hypothesis, we find that women were consuming more FV but are less likely to meet PA recommendations which is supported by other studies [34-37]. In contrast to other studies and our hypothesis, we find that rural residents were more likely to be meeting PA recommendations $[12,38]$. We did not support our hypothesis for a disparity in FV intake between rural and urban residents; however, the region-wide FV intake is very low. Efforts targeting increases in FV intake as part of an obesity prevention/reduction strategy could yield other health benefits to local residents. Further, regular PA confers a variety of health benefits that could improve other chronic health indicators (i.e. hypertension, diabetes) and reduce obesity. 


\section{Strengths \& limitations}

This study is not without limitations. First, all telephone surveys, even with random sampling, have limitations for those who are likely to be contacted. Likewise, all survey data is fallible to self-report bias. We aimed to minimize these biases by including both land-lines and cell numbers and using previously validated survey instruments. Furthermore, these data represent a cross-sectional regional surveillance survey that provides a snapshot of the health indicators and may have limited generalizability outside the DRR. However, there is a clear need for local data, particularly for service partners working with these populations. The prevalence of health indicators on a local scale are important to identify target populations for programs, to promote decision making among local health and community organizations, and to allow for efficient use of resources.

\section{Conclusions}

While obesity has been the primary focus of the DRPHC since its initiation in 2009 [23], these findings represent the first locally generated data to substantiate the region-wide magnitude of obesity-related health disparities within the DRR. The high prevalence of obesity, coupled with the low proportion of residents meeting FV and PA recommendations, clearly suggests that residents could benefit from primary prevention efforts and programming aimed at increasing positive health behaviors. Further, programming that targets those with BMIs $>30$ may be most effective in reducing obesity prevalence in the region. In particular, blacks, urban residents at the upper end of the BMI distribution appear to be at particular risk with prevalence in excess of their peers. Therefore, working with local partners from the DRPHC such as public health departments, public housing and parks and recreation to develop and implement programming that targets these hard to reach and vulnerable groups may be important next steps.

Finally, these data create an essential baseline for the ongoing work of the DRPHC. Measuring effectiveness is difficult for any coalition, and often effectiveness is measured by the success of a single program or intervention $[39,40]$. Notably, this survey provides critical regional data that creates a benchmark to measure the success of obesity reduction efforts by the DRPHC over time. For example, since the time this survey was conducted, numerous research projects prioritized by the DRPHC have been launched, including objective assessments of the built environment [41,42], a community-garden initiative [43], a pilot behavioral intervention targeting adult obesity [44], and a recently funded childhood obesity treatment planning grant [45]. Given the mission to reduce obesity, the DRPHC has the growing capacity to determine the potential public health impact of current and future obesity-related efforts in the region. Importantly, these surveillance data will be disseminated at the regional level through established partners and networks of the DRPHC, with the hopes of informing agenda setting and maximizing the development and implementation of high impact obesity reduction programs.

\section{Competing interests}

The authors declare that they have no competing interests. All authors were affiliated with Virginia Tech at the time this research was conducted.

\section{Authors' contributions}

$J H, W Y$ and JZ conceptualized and drafted the paper. Each author contributed to further development and revisions of the paper, and approved the final submission. Each author assumed a unique role in execution of this research: $\mathrm{JH}$ secured grant funding and conceptualized the study design; JH and JZ developed the survey and implemented study protocol; WY conducted the analysis, including expertise on data modeling. All authors contributed to the interpretation of results and final conclusions of the article.

\section{Acknowledgements}

The project described was supported in part by funding from the College of Agriculture and Life Sciences (CALS) at Virginia Tech and Virginia Tech's

Open Access Subvention Fund. The authors would like to recognize contributions to this effort from Center for Survey Research at Virginia Tech and graduate research assistants who assisted in the creation and testing of the survey. Further, we would like to extend our appreciation to our community partners and the Dan River Partnership for a Healthy Community.

\section{Author details}

'Department of Human Nutrition, Foods and Exercise, Virginia Tech, Blacksburg, Virginia, USA. ${ }^{2}$ Department of Agriculture and Applied Economics, Virginia Tech, Blacksburg, Virginia, USA.

Received: 24 January 2014 Accepted: 24 September 2014

Published: 8 October 2014

\section{References}

1. Flegal KM, Carroll MD, Kit BK, Ogden CL: Prevalence of obesity and trends in the distribution of body mass index among US adults, 1999-2010. JAMA 2012, 307(5):491-497.

2. Flegal KM, Carroll MD, Ogden CL, Curtin LR: Prevalence and trends in obesity among US adults, 1999-2008. JAMA 2010, 303(3):235-241.

3. Ogden $\mathrm{CL}$, Carroll MD, Curtin LR, McDowell MA, Tabak CJ, Flegal KM: PRevalence of overweight and obesity in the United States, 1999-2004. JAMA 2006, 295(13):1549-1555.

4. Jackson CL, Szklo M, Yeh HC, Wang NY, Dray-Spira R, Thorpe R, Brancati FL: Black-white disparities in overweight and obesity trends by educational attainment in the United States, 1997-2008. J Obes 2013, 2013:140743.

5. U.S. Department of Health and Human Services. Office of Disease Prevention and Health Promotion: Healthy People 2020. In Washington, DC: http://www. healthypeople.gov/2020/default.aspx. Accessed September 2014.

6. Wang Y, Beydoun MA: The obesity epidemic in the United States-gender, age, socioeconomic, racial/ethnic, and geographic characteristics: a systematic review and meta-regression analysis. Epidemiol Rev 2007, 29(1):6-28.

7. Zhang Q, Wang YF: Trends in the association between obesity and socioeconomic status in US adults: 1971 to 2000 . Obes Res 2004 12(10):1622-1632.

8. Agency for Healthcare Research and Quality: National Healthcare Disparities Report 2013. In http://www.ahrq.gov/research/findings/nhqrdr/ nhar13/index.html. Updated 2013. Accessed 2014.

9. Bellamy GR, Bolin JN, Gamm LD: Rural healthy people 2010, 2020 and beyond: the need goes on. Fam Community Health 2011, 34(2):182-188.

10. Jackson JE, Doescher MP, Jerant AF, Hart LG: A national study of obesity prevalence and trends by type of rural county. J Rural Health 2005, 21(2):140-148.

11. Tai-Seale T, Chandler C: Nutrition and Overweight Concerns in Rural Areas: A Literature Review. Rural Healthy People 2010: A Companion Document to Healthy People 2010.. College Station, TX: Texas A\&M University; 2003. 
12. Patterson PD, Moore CG, Probst JC, Shinogle JA: Obesity and physical inactivity in rural America. J Rural Health 2004, 20(2):151-159.

13. Eberhardt MS, Pamuk ER: The importance of place of residence: examining health in rural and nonrural areas. Am J Public Health 2004 94(10):1682-1686.

14. Befort CA, Nazir N, Perri MG: Prevalence of obesity among adults from rural and urban areas of the United States: findings from NHANES (2005-2008). J Rural Health 2012, 28(4):392-397.

15. Probst JC, Moore CG, Glover SH, Samuels ME: Person and place: the compounding effects of race/ethnicity and rurality on health. Am J Public Health 2004, 94(10):1695-1703.

16. Medically Underserved Areas/Populations. U.S. Department of Health and Human Services, Health Resources and Services Administration; [http://muafind.hrsa.gov/].

17. Berkowitz B: Rural public health service delivery: promising new directions. Am J Public Health 2004, 94(10):1678-1681.

18. Phillips CD, McLeroy KR: Health in rural America: remembering the importance of place. Am J Public Health 2004, 94(10):1661-1663.

19. Hartley D: Rural health disparities, population health, and rural culture. Am J Public Health 2004, 94(10):1675-1678.

20. Minkler M, Wallerstein N: Community Based Participatory Research for Health: From process to outcomes. 2nd edition. San Francisco: Jossey Bass; 2008.

21. Wallerstein NB: Community-based participatory research contributions to intervention research: the intersection of science and practice to improve health equity. Am J Public Health 2010, 100(S1):S40-S46.

22. Israel BA: Methods in Community-based Participatory Research for Health. San Francisco: CA Jossey-Bass; 2005.

23. Zoellner J, Motley M, Wilkinson ME, Jackman B, Barlow ML, Hill JL: Engaging the Dan river region to reduce obesity: application of the comprehensive participatory planning and evaluation process. Fam Community Health 2012, 35(1):44-56.

24. Motley MHA, Hill JL, Plubm K, Zoellner JM: Evaluating community capacity to address obesity in the dan river region: a case study. Am J Health Behav 2013, 37(2):207-216.

25. Virginia Department of Health: Unequal Health Across the Commonwealth: A Snapshot. In Virginia Health Equity Report. Richmond, VA: Virginia Department of Health: Office of Minority Health \& Public Health Policy; 2008:1-222

26. U.S. Department of Health and Human Services Health Resources and Services Administration: Find Shortage Areas for Medically Underserved Areas/Populations. In http://muafind.hrsa.gov/. Published 2014. Accessed September 2014

27. Woolf SH, Jones RM, Johnson RE, Phillips RL Jr, Oliver MN, Bazemore A, Vichare A: Avertable deaths associated with household income in Virginia. Am J Public Health 2010, 100(4):750-755.

28. US Census Bureau: State and County Quick Facts. In http://quickfacts. census.gov. Published 2010. Accessed 2012.

29. US Department of Agriculture: Rural Urban Commuting Area Codes. In http://www.ers.usda.gov/data-products/rural-urban-continuum-codes.aspx\#. VDwXDOfKPUc. Published 2010. Accessed August 2014

30. (CDC) Centers for Disease Control and Prevention: Behavioral Risk Factor Surveillance System Survey Data. Atlanta, Georgia: U.S: Department of Health and Human Services, Centers for Disease Control and Prevention; 2011.

31. Godin G, Shephard RJ: A simple method to assess exercise behavior in the community. Can J App/ Sport Sci 1985, 10(3):141-146.

32. U.S. Department of Health and Human Services: Physical Activity Guidelines for American. In http://www.health.gov/paguidelines/ guidelines/. Published 2008. Accessed June 2012.

33. Thompson FE, Subar AF, Smith AF, Midthune D, Radimer KL, Kahle LL, Kipnis V: Fruit and vegetable assessment: performance of 2 new short instruments and a food frequency questionnaire. J Am Diet Assoc 2002, 102(12):1764-1772.

34. Centers for Disease Control and Prevention: Adult participation in aerobic and muscle-strengthening physical activities-United States, 2011. MMWR Morb Mortal Wkly Rep 2013, 62(17):326-330.

35. Lutfiyya $M$, Chang L, Lipsky M: A cross-sectional study of US rural adults' consumption of fruits and vegetables: do they consume at least five servings daily? BMC Public Health 2012, 12(1):280.

36. Dean WR, Sharkey JR: Rural and urban differences in the associations between characteristics of the community food environment and fruit and vegetable intake. J Nutr Educ Behav 2011, 43(6):426-433.
37. Dubowitz T, Heron M, Bird CE, Lurie N, Finch BK, Basurto-Davila R, Hale L, Escarce JJ: Neighborhood socioeconomic status and fruit and vegetable intake among whites, blacks, and Mexican Americans in the United States. Am J Clin Nutr 2008, 87(6):1883-1891.

38. Parks SE, Housemann RA, Brownson RC: Differential correlates of physical activity in urban and rural adults of various socioeconomic backgrounds in the United States. J Epidemiol Community Health 2003, 57(1):29-35.

39. Cargo M, Mercer SL: The value and challenges of participatory research: strengthening its practice* $\neq$. Annu Rev Public Health 2008, 29(1):325-350.

40. PolicyLink: Promoting Healthy Public Policy through Community-Based Participatory Research: Ten Case Studies. In 2008. Available at http://www. policylink.org/sites/default/files/CBPR_PromotingHealthyPublicPolicy_final. pdf Accessed 2012

41. Hill J, Chau C, Luebbering C, Kolivras K, Zoellner J: Does availability of physical activity and food outlets differ by race and income? Findings from an enumeration study in a health disparate region. Int J Behav Nutr Phys Act 2012, 9(1):105

42. Chau CN, Zoellner JM, Hill JL: Availability of healthy food: does block group race and income matter? J Hunger Environ Nutr 2013, 8(1):22-38

43. Zoellner J, Zanko AM, Price B, Bonner J, Hill JL: Exploring community gardens in a health disparate population: findings from a mixed methods pilot study. Prog Community Health Partnership 2012, 6(2):12

44. Zoellner J, Hill JL, Grier K, Chau C, Kopec D, Price B, Dunn C: Randomized controlled trial targeting obesity-related behaviors: better together healthy caswell county. Prev Chronic Dis 2013, 10:E96.

45. Dan River Partnership for a Healthy Community. DRHealthy Community: In 2014. Available at http://www.drhealthycommunity.org/. Accessed September 2014

\section{doi:10.1186/1471-2458-14-1051}

Cite this article as: Hill et al:: Disparities in obesity among rural and urban residents in a health disparate region. BMC Public Health 2014 14:1051.

\section{Submit your next manuscript to BioMed Central and take full advantage of:}

- Convenient online submission

- Thorough peer review

- No space constraints or color figure charges

- Immediate publication on acceptance

- Inclusion in PubMed, CAS, Scopus and Google Scholar

- Research which is freely available for redistribution

Submit your manuscript at www.biomedcentral.com/submit
C Biomed Central 